\title{
Educational Accommodations for Students With Disabilities: Two Equity-Related Concerns
}

\author{
Benjamin J. Lovett* \\ School Psychology Program, Teachers College, Columbia University, New York, NY, United States
}

Educational accommodations are frequently given to students with disabilities. For instance, students might be given a copy of class notes or provided additional time to complete a test. One purpose of accommodations is to improve educational equity, putting all students on equal footing. However, research on current accommodations practices raises two distinct equity-related concerns. First, students from privileged backgrounds are more likely to receive certain accommodations even without adequate evidence of need; this can provide an unfair boost in performance and widen gaps among students. Second, when students from less privileged backgrounds are given accommodations, the incentive for schools to provide

OPEN ACCESS

Edited by:

Joseph Madaus,

University of Connecticut,

United States

Reviewed by:

Jennifer $H$. Lindstrom,

University of Georgia, United States

Leanne R. Ketterlin Geller,

Southern Methodist University,

United States

*Correspondence:

Benjamin J. Lovett

BL2799@tc.columbia.edu

Specialty section:

This article was submitted to Educational Psychology,

a section of the journal

Frontiers in Education

Received: 14 October 2021 Accepted: 10 November 2021

Published: 06 December 2021

Citation:

Lovett BJ (2021) Educational Accommodations for Students With

Disabilities: Two Equity-

Related Concerns.

Front. Educ. 6:795266.

doi: 10.3389/feduc.2021.795266 academic remediation, compensatory strategies, and coping skills is lessened, leaving these students in a worse position when accommodations are not available outside of educational settings. Implications for practice are discussed.

Keywords: educational accommodations, students with disabilities, educational equity, disability accommodations, assessment

\section{INTRODUCTION}

Educational accommodations are alterations made to the delivery of instruction or testing, while keeping the essential content the same (Lovett and Lewandowski, 2015). ${ }^{1}$ Such accommodations are frequently provided to students who have been diagnosed with disabilities. For instance, a student with attention-deficit/hyperactivity disorder (ADHD) might be permitted to take tests in a separate location, due to concerns that the student is unusually prone to distraction, and that their performance would be unduly affected by taking the test in a typical classroom full of ambient noises. Similarly, the student might be given preferential seating during instruction, always being seated close to the teacher, to help the student focus on the teacher and not be distracted by peers. These accommodations would not change the content of the test or curriculum, just their delivery.

Accommodations can be distinguished from interventions, in that accommodations are designed to adjust the task requirements for a student in some way, without directly altering the student's skill levels. In contrast, interventions attempt to change the student's skill levels, so that the student can participate in a school's instruction and assessment practices in their typical delivery formats.

${ }^{1}$ Some sources distinguish between accommodations and modifications; however, this distinction is not always made in consistent ways, and the same alteration might be considered an accommodation in one situation and a modification in another (Lovett and Lewandowski, 2015). Therefore, I use the term accommodations throughout. 
In the United States, it appears that accommodations are the most common response to disability diagnoses in school settings. Recent research finds that the vast majority of students with disabilities receive accommodations, and it appears that accommodations are more frequently recommended and implemented than evidence-based interventions are. Kern et al. (2019) inspected the special education plans (IEP documents) of 222 students in secondary school, most of whom had diagnoses of a learning disability, an emotional/ behavioral disorder, or a health impairment. Collectively, the IEP documents listed 1,840 accommodations for these students. The most common accommodations were extended time to complete tests and assignments, and having tests read aloud and in a small group setting. Burns et al. (2020) reviewed school psychologists' evaluation reports for 130 students, to determine what services these professionals recommended. Burns et al. (2020) found that the three most common recommendations made were for accommodations: extended time, breaking tasks into smaller units, and preferential seating. Recommendations for interventions were substantially rarer. Finally, Hustus et al. (2020) reviewed special education and disability accommodation plans for 183 secondary school students with ADHD, and also found that accommodations were among the most common services provided. Specifically, these investigators expressed concern that many students with behavior problems (a common issue in ADHD) were not given special education goals related to improving behavior, as accommodations were apparently viewed as more acceptable.

Given that accommodations are so prevalent, and that school professionals seem to naturally respond to disability identification by proposing accommodations, it is important to explore whether they are serving their intended purposes. The present paper focuses on one such purpose: equity of educational opportunity.

\section{ACCOMMODATIONS AND EDUCATIONAL EQUITY}

"Educational equity" does not have a single consensus definition, but it generally includes concepts such as fairness in educational opportunities across students from different backgrounds (for a classic statement, see Gordon, 1976). A goal of equity has long been applied to special education efforts as well (McLaughlin, 2010). Historically, students with disabilities were often either a) denied educational opportunities entirely, b) provided with grossly substandard opportunities due to inappropriately low expectations for their potential, or c) placed in standard educational settings without the supports needed for meaningful participation in those settings. It is the latter problem that is most relevant to accommodations, since accommodations are supports meant to help "level the playing field" (Byrnes, 2008), allowing students with disabilities to participate fairly alongside their nondisabled peers. Used well, accommodations promote educational equity, by allowing students to access educational opportunities. For instance, a blind student cannot meaningfully participate in a chemistry test administered in a standard paper-and-pencil format. The student's score on a such a test would be a reflection of their visual acuity rather than their knowledge of chemistry. With an accommodation, such as reading the test items aloud and recording the student's oral responses, meaningful participation in the testing process can be achieved. The logic of accommodations is easiest to understand in relation to sensory and physical disabilities, but they can be just as relevant to other disability conditions. For instance, a child with a severe reading disability (and who is unable to decode many words correctly) may also need read-aloud accommodations on some tests.

To be clear, equity of educational opportunity does not guarantee equal outcomes, and even with accommodations, students with disabilities often underperform relative to their nondisabled peers. Accommodations are designed to allow for access to educational opportunities, not necessarily success in a particular educational endeavor. These goals can become conflated because accommodations often do raise the performance of students with disabilities (Sireci et al., 2005), and thus reduce the gap in outcomes between these students and nondisabled peers. However, the two goals are logically distinct, and have very different implications for equity-based accommodations practices. Pressure for improvement in superficial indicators of performance (e.g., scores on tests) can lead students to receive inappropriate accommodations. This presents in two forms: more privileged students seeking further performance gains, and less privileged students receiving accommodations instead of needed interventions. Both phenomena work against genuine equity of educational opportunity.

\section{SOCIAL ADVANTAGE AND ACCOMMODATION AVAILABILITY}

Educational accommodations provide a benefit to those who receive them, and like any benefit, the distribution of accommodations should be fair. Students should receive accommodations just because those accommodations are needed for access to educational programming. The chances of obtaining accommodations should not be due to irrelevant factors, such as demographic features (e.g., gender and ethnicity) that often raise concerns about potential discrimination.

Unfortunately, the available research suggests that demographic factors do play a causal role in determining whether a student will receive accommodations. Specifically, students with higher socioeconomic status (which does vary by ethnicity) are more likely than their peers to receive accommodations. In the United States, this has been investigated via the analysis of "Section 504 plans"-educational accommodation plans that students receive, typically for relatively mild disorders and disabilities where comprehensive special education is not needed, only accommodations. In 2019, two sets of investigative reporters at the New York Times and Wall Street Journal performed independent analyses of the prevalence of Section 504 plans in many high schools, where each school was coded by income level (Belkin et al., 2019; Goldstein and Patel, 2019). Both investigations found large 
differences in 504 plan prevalence by income level. For instance, the New York Times found students in the wealthiest $20 \%$ of schools were almost twice as likely as students in the poorest $20 \%$ of schools to have 504 plans. Students in the wealthiest $1 \%$ of schools were almost four times as likely to have 504 plans as were students in the poorest $1 \%$ of schools. Although accommodations are expected to specifically address disability-related deficits, and therefore differentially raise performance of student with disabilities, some studies have found that accommodations boost performance in students with and without disabilities (for reviews of relevant studies, see Royer and Randall, 2012; Sireci et al., 2005), and since wealth is already a predictor of educational outcomes, differential provision of accommodations to the wealthy contributes to widening gaps in performance.

Some may wonder if the richer schools are truly overproviding accommodations, or whether they are simply providing what all schools should. The latter possibility is unlikely; the Wall Street Journal investigation report described specific wealthy schools with implausible rates of disability identification, including one (Newton North High school, in a suburb of Boston) where onethird of the students received 504 plans. Such rates of disability are improbable on their face-indeed, taken literally, they would suggest a public health crisis. Nationally, only about $1 \%$ of students have solely 504 plans (Zirkel and Weathers, 2014), and 14\% have IEPs (Institute of Education Sciences, 2021). It is even odder that such high rates of disability would be present in a wealthy district, since poverty leads to higher rates of genuine disabilities through a variety of mechanisms (e.g., poor prenatal care, inadequate housing, less linguistic and cognitive stimulation, etc.; Brooks-Gunn and Duncan, 1997).

How does wealth lead to implausible rates of disability identification and (therefore) inappropriate accommodations? First, sociological research has found that wealthier parents are more involved in their children's education and more likely to request accommodations (e.g., Calarco, 2018). Second, wealthier parents are better able to afford independent disability evaluations from private-practice and hospital-based diagnosticians, who have a significant financial incentive (i.e., direct payment by the parents) to make diagnoses and accommodations recommendations that the customers are seeking (Roberts, 2012). (To be clear, public school districts must provide free disability evaluations by parental request, but school district employees lack a direct financial incentive to recommend desired accommodations, especially when children are doing well in school). Finally, students from privileged families are more likely to be under intense pressure from parents and schools to achieve at extremely high levels (Luthar et al., 2020), leading to a search for any supports (e.g., subject-area tutors, executive function coaches, and educational accommodations) to make that achievement possible. These students are apt to feel in competition with peers in the same high-achieving environment, rather than judging themselves against expectations for the general population or criterionreferenced standards such as skill mastery. Therefore, accommodations become a critical tool in outperforming peers, and as the frequency of accommodations in wealthy settings rises, any students without accommodations are indeed at a disadvantage in relative terms.
If accommodations only had effects on students with relevant disabilities, this would not be especially problematic. However, accommodations often boost the performance and assuage the anxiety of students both with and without disabilities. The most common accommodation-extended time on tests-has repeatedly been found to raise the performance of students regardless of disability status (Cahan et al., 2016). More generally, accommodations tend to make all students feel more comfortable when taking a test (Lovett and Leja, 2013)another key reason why they are sought.

When accommodations are provided to more privileged students who do not actually need them, the accommodations function as an unfair advantage that increases inequities in both educational access and performance outcomes. An extreme "natural experiment" of sorts illustrating this phenomenon came to light in 2019, when it was revealed that a group of wealthy parents had asked their children to feign disabilities to get accommodations on college admissions tests (for analysis, see Lovett, 2020). While an unusual event in and of itself, the 2019 college admissions scandal relied on the very same processes operating to provide accommodations to relatively privileged students every day.

\section{ACCOMMODATIONS VS. INTERVENTIONS FOR DISADVANTAGED STUDENTS}

When seeing the unequal rates of accommodations provided across socioeconomic classes, it may be tempting to simply provide more accommodations to less privileged students. Certainly, many students in this population need and fully deserve accommodations to access their educational programs. However, even here, accommodations are often used too readily, and with different but still quite problematic effects on educational equity.

This issue is raised well by a recent study, the first and only randomized controlled trial comparing accommodations to interventions, for students aged 11-15 with ADHD (Harrison et al., 2020). Students in the accommodation group were given organizational support (an assistant would organize their assignments for them in their binder), a copy of class notes, and $50 \%$ additional time to complete assignments. Students in the intervention condition were instead given training in how to organize their own assignments (i.e., instruction and practice with feedback), instruction in how to take class notes, and a computerized intervention to train sustained attention skills. Student performance and behavior were compared between the two groups a) at baseline, b) after a period of the interventions or accommodations, and c) at a later follow-up after the interventions or accommodations had been withdrawn. At the end of the treatment, the students in the intervention group outperformed those in the accommodation group (e.g., took better class notes, were more engaged in class, completed more assignments correctly), and these differences remained at follow-up, sometimes becoming even greater in magnitude. The accommodations not only failed to teach skills, but actually seemed to reduce motivation to acquire skills; for instance, if a 
student received a copy of the teacher's class notes, what was the incentive for them to take good notes themselves? The corollary effect of all this on equity is evident; as students (with ADHD) who are more impaired than their peers receive inappropriate accommodations, their skills do not develop, while their classmates' skills do, and the skill gaps grow as the classmates receive more experience practicing their skills whereas the students with ADHD fall farther and farther behind. For a time, accommodations may artificially prop up the performance of the students with $\mathrm{ADHD}$, but at some point (even if not until exiting the educational system), accommodations are withdrawn, and the students are left without skills that their schools could have been developing. In youth from disadvantaged backgrounds, such skills are all the more critical for success in life, as these youth lack other privileges.

A similar problem happens when accommodations are given for emotional disorders, particularly anxiety. Qualitative research suggests that student anxiety is a common basis for accommodation decisions by school staff (Rickey, 2005), but a large literature in the field of child clinical psychology has found that accommodating anxiety tends to make it worse over the long term (for review, see Kagan et al., 2017). Admittedly, most studies have examined accommodations made by family members-for instance, not visiting relatives who own a dog because the child has a fear of dogs. However, the same principles apply to school-based accommodations, with anxiety disorder experts warning that accommodations help students to avoid situations that they must learn to cope with. In one survey study (Conroy et al., 2020), experts expressed particular concern about reducing grading standards, allowing additional time, and waiving class participation requirements in response to anxiety. Again, the goal of school staff should be to teach coping skills, and school mental health staff (school psychologists, school counselors) can offer evidencebased interventions to reduce anxiety. Such interventions typically contain, as the central active ingredient, exposure to the feared situation (Whiteside et al., 2020). Students from privileged backgrounds may be able to afford (literally) to continue avoiding anxiety-provoking situations, but disadvantaged students cannot, and school is a place where they can receive skills to handle such situations, rather than receiving support for their avoidance.

The cases of ADHD and anxiety illustrate how providing accommodations along with interventions is sometimes untenable, since the accommodations take away any motivation to participate in the difficult work of the interventions. Indeed, in the case of anxiety, accommodation has been found to work against intervention effects when the two are present together (for a vivid clinical example, see Rudy et al., 2015). This does not mean that accommodations are never appropriate; of course, they can be critical parts of an educational program. However, interventions should generally be attempted first. This approach is in keeping with modern Multi-Tiered Systems of Support (MTSS) approaches to special education delivery, where students are provided increasingly intensive interventions and only considered for formal disability classification and services such as accommodations after multiple interventions fail (Jimerson et al., 2016). Of course, where appropriate, students can be provided with IEPs, and the objectives on the IEPs can be attained using evidence-based interventions. The problem occurs when IEPs are used to provide inappropriate accommodations, essentially giving up trying to help students increase academic skill levels and other age-appropriate competencies.

The incentives to provide inappropriate accommodations to privileged youth were easy enough to see; in contrast, the incentives in settings for disadvantaged youth often relate to the stress of school staff working in high-need areas, where taking on additional intervention cases is far more difficult and time-consuming than simply providing accommodations that-for the time being- "solve" the problem. Indeed, Conroy et al. (2020) found that school staff who reported higher levels of emotional exhaustion were more likely to use accommodations that simply allowed students with anxiety to avoid dealing with whatever they were afraid of. We should sympathize with overworked and undertrained individual school staff members, while nonetheless realizing that school systems abrogate their legal and ethical responsibility to disadvantaged youth by providing superficial accommodations rather than addressing skill deficits. These youth then go into education or employment settings where even if they receive some type of disability supports, they still lack adequate academic skills to lead to likely success (Sparks and Lovett, 2013).

\section{DISCUSSION}

Educational accommodations are one tool for allowing students with disabilities to participate in educational programs meaningfully. Certainly, for many youth with disabilities, these kinds of adjustments are appropriate, and when they allow access to instruction, accommodations lead to skill development, which in turn helps to lessen gaps between students with and without disabilities. In short, used well, accommodations are a tool for educational equity. Unfortunately, accommodations are often misused. As I have discussed, some of the misuses actually actively impede educational equity goals, either by giving privileged students unfair advantages or by denying disadvantaged students needed training in academic, organizational, and coping/emotional skills.

The solution to this problem is not to give in to wholesale skepticism about accommodations (e.g., Lerner, 2004). Instead, accommodation decisions must be made carefully, based on individualized data about the student and the educational program in question. In a seminal treatment of the issue, Phillips (1994) suggested several questions to be asked when making accommodation decisions. Two of those questions are particularly pertinent to the present paper: 1) Would the accommodation benefit nondisabled students as well? 2) Can the student with a disability adapt to standard conditions? When the answer to the first question is "yes," we should explore whether the accommodation is just an unfair performance booster, and when the answer to the second question is "yes," we should try to implement an intervention rather than an accommodation. Considerations like these, as part of a 
structured decision-making approach, can lead to accommodations that serve their intended purposes, including addressing inequities in educational opportunities.

\section{AUTHOR'S NOTE}

Author (initials) consults professionally on accommodations issues and earns royalties from the sale of a book on the topic.

\section{REFERENCES}

Belkin, D., Levitz, J., and Korn, M. (2019). Many More Students, Especially the Affluent, Get Extra Time to Take the SAT. Wall Street Journal. Available at: wsj.com.

Brooks-Gunn, J., and Duncan, G. J. (1997). The Effects of Poverty on Children. Future Child. 7, 55-71. doi:10.2307/1602387

Burns, M. K., Barrett, C. A., Maki, K. E., Hajovsky, D. B., Duesenberg, M. D., and Romero, M. E. (2020). Recommendations in School Psychological Evaluation Reports for Academic Deficits: Frequency, Types, and Consistency with Student Data. Contemp. Sch. Psychol 24 (4), 478-487. doi:10.1007/s40688-020-00313-w

Byrnes, M. (2008). Writing Explicit, Unambiguous Accommodations. Intervention Sch. Clinic 44 (1), 18-24. doi:10.1177/1053451208318679

Cahan, S., Nirel, R., and Alkoby, M. (2016). The Extra-examination Time Granting Policy. J. Psychoeducational Assess. 34 (5), 461-472. doi:10.1177/0734282915616537

Calarco, J. M. (2018). Negotiating Opportunities. New York: Oxford University Press.

Conroy, K., Greif Green, J., Phillips, K., Poznanski, B., Coxe, S., Kendall, P. C., et al. (2020). School-based Accommodations and Supports for Anxious Youth: Benchmarking Reported Practices against Expert Perspectives. J. Clin. Child Adolesc. Psychol., 1-9. doi:10.1080/15374416.2020.1723601

Goldstein, D., and Patel, J. K. (2019). Need Extra Time on Tests? it Helps to Have Cash. New York, United States: New York Times. Available at: www.nytimes.com.

Gordon, E. W. (1976). Toward an Understanding of Educational Equity. Available at: https://files.eric.ed.gov/fulltext/ED128514.pdf.

Harrison, J. R., Evans, S. W., Baran, A., Khondker, F., Press, K., Noel, D., et al. (2020). Comparison of Accommodations and Interventions for Youth with ADHD: A Randomized Controlled Trial. J. Sch. Psychol. 80, 15-36. doi:10.1016/ j.jsp.2020.05.001

Hustus, C. L., Evans, S. W., Owens, J. S., Benson, K., Hetrick, A. A., Kipperman, K., et al. (2020). An Evaluation of 504 and Individualized Education Programs for High School Students with Attention Deficit Hyperactivity Disorder. Sch. Psychol. Rev. 49 (3), 333-345. doi:10.1080/2372966x.2020.1777830

Institute of Education Sciences (2021). Report on the Condition of Education 2021. Washington, D.C., United States: U.S. Department of Education.

Kagan, E. R., Frank, H. E., and Kendall, P. C. (2017). Accommodation in Youth with OCD and Anxiety. Clin. Psychol. Sci. Pract. 24 (1), 78-98. doi:10.1111/cpsp.12186

Kern, L., Hetrick, A. A., Custer, B. A., and Commisso, C. E. (2019). An Evaluation of IEP Accommodations for Secondary Students with Emotional and Behavioral Problems. J. Emotional Behav. Disord. 27 (3), 178-192. doi:10.1177/1063426618763108

Lerner, C. S. (2004). “Accommodations” for the Learning Disabled: A Level Playing Field or Affirmative Action for Elites? Vanderbilt L. Rev 57 (3), 1043-1124.

Lovett, B. J. (2020). Disability Identification and Educational Accommodations: Lessons from the 2019 Admissions Scandal. Educ. Res. 49 (2), 125-129. doi:10.3102/0013189x20902100

Lovett, B. J., and Leja, A. M. (2013). Students' Perceptions of Testing Accommodations: What We Know, what We Need to Know, and Why it Matters. J. Appl. Sch. Psychol. 29 (1), 72-89. doi:10.1080/15377903.2013.751477

Lovett, B. J., and Lewandowski, L. J. (2015). Testing Accommodations for Students with Disabilities: Research-Based Practice. Washington, DC: American Psychological Association.

Luthar, S. S., Kumar, N. L., and Zillmer, N. (2020). High-achieving Schools Connote Risks for Adolescents: Problems Documented, Processes

\section{AUTHOR CONTRIBUTIONS}

BL wrote and edited the article in its entirety.

\section{ACKNOWLEDGMENTS}

The author thanks Marla Brassard for her comments on a draft of this article.

Implicated, and Directions for Interventions. Am. Psychol. 75 (7), 983-995. doi:10.1037/amp0000556

McLaughlin, M. J. (2010). Evolving Interpretations of Educational Equity and Students with Disabilities. Exceptional Child. 76 (3), 265-278. doi:10.1177/ 001440291007600302

Phillips, S. E. (1994). High-stakes Testing Accommodations: Validity versus Disabled Rights. Appl. Meas. Edu. 7 (2), 93-120. doi:10.1207/ s15324818ame0702_1

Rickey, K. M. (2005). “Assessment Accommodations for Students with Disabilities: A Description of the Decision-Making Process, Perspectives of Those Affected, and Current Practices,". Unpublished dissertation (Iowa City, Iowa: University of Iowa).

Roberts, B. L. (2012). Beyond Psychometric Evaluation of the Student-Task Determinants of Accommodation. Can. J. Sch. Psychol. 27 (1), 72-80. doi: $10.1177 / 0829573512437171$

Royer, J. M., and Randall, J. (2012). “Testing Accommodations for Students with Disabilities," in APA Educational Psychological Handbook: Vol. 3. Application to Learning and Teaching. Editors K. R. Harris, S. Graham, and T. Urdan (Washington, DC: American Psychological Association). doi:10.1037/ 13275-007

Rudy, B. M., Storch, E. A., and Lewin, A. B. (2015). When Families Won't Play Ball: A Case Example of the Effect of Family Accommodation on Anxiety Symptoms and Treatment. J. Child. Fam. Stud. 24 (7), 2070-2078. doi:10.1007/s10826014-0008-3

Sireci, S. G., Scarpati, S. E., and Li, S. (2005). Test Accommodations for Students with Disabilities: An Analysis of the Interaction Hypothesis. Rev. Educ. Res. 75 (4), 457-490. doi:10.3102/00346543075004457

Sparks, R. L., and Lovett, B. J. (2013). Applying Objective Diagnostic Criteria to Students in a College Support Program for Learning Disabilities. Learn. Disabil. Q. 36 (4), 231-241. doi:10.1177/0731948712472185

S. R. Jimerson, M. K. Burns, and A. M. Van Der Heyden (Editors) (2016) Handbook of Response to Intervention (New York: Springer).

Whiteside, S. P. H., Sim, L. A., Morrow, A. S., Farah, W. H., Hilliker, D. R., Murad, M. H., et al. (2020). A Meta-Analysis to Guide the Enhancement of CBT for Childhood Anxiety: Exposure over Anxiety Management. Clin. Child. Fam. Psychol. Rev. 23 (1), 102-121. doi:10.1007/s10567-019-00303-2

Zirkel, P. A., and Weathers, J. M. (2014). Section 504-only Students: National Incidence Data. J. Disabil. Pol. Stud. 26 (3), 184-193.

Conflict of Interest: The author declares that the research was conducted in the absence of any commercial or financial relationships that could be construed as a potential conflict of interest.

Publisher's Note: All claims expressed in this article are solely those of the authors and do not necessarily represent those of their affiliated organizations, or those of the publisher, the editors and the reviewers. Any product that may be evaluated in this article, or claim that may be made by its manufacturer, is not guaranteed or endorsed by the publisher.

Copyright (C) 2021 Lovett. This is an open-access article distributed under the terms of the Creative Commons Attribution License (CC BY). The use, distribution or reproduction in other forums is permitted, provided the original author $(s)$ and the copyright owner(s) are credited and that the original publication in this journal is cited, in accordance with accepted academic practice. No use, distribution or reproduction is permitted which does not comply with these terms. 